\title{
Palmar-Plantar
}

\section{Erythrodysesthesia Associated with Chemotherapy and Its Treatment}

\author{
Katherina Podlekareva Farr Akmal Safwat \\ Department of Oncology, Aarhus University Hospital, Aarhus, Denmark
}

\section{Key Words}

Palmar-plantar erythrodysesthesia $\cdot$ Hand-foot syndrome $\cdot$ Pegylated liposomal doxorubicin

\begin{abstract}
Palmar-plantar erythrodysesthesia (PPE), also called hand-foot syndrome, is a relatively common dermatologic toxic reaction associated with cytotoxic chemotherapy that can limit the use of such drugs. Definitive prevention and treatment strategies for PPE have not yet been established. We present a patient with recurrent ovarian cancer developing severe hand-foot syndrome after treatment with pegylated liposomal doxorubicin. A review of the relevant literature concerning pathophysiology, preventive measures and management of PPE is given. Electronic search was conducted using the Medline database for English-language records. The search terms used were 'palmar-plantar erythrodysesthesia', 'hand-foot syndrome', 'pegylated liposomal doxorubicin' and 'acral erythema'.
\end{abstract}

\section{Case Report}

A 69-year-old woman diagnosed with clinical stage IV platinum-refractory ovarian carcinoma received pegylated liposomal doxorubicin (PLD) treatment at a dose of $50 \mathrm{mg} / \mathrm{m}^{2}$ every 4 weeks. After three treatments the patient had mild erythema and swelling and tingling of the hands, which did not interfere with her daily activities. This was evaluated as grade 1 palmar-plantar erythrodysesthesia (PPE), so-called hand-foot syndrome. The patient was advised to apply cream and to avoid extreme temperatures and excessive pressure or friction to the skin. Dose modification of PLD was not indicated (table 1). After the fourth treatment the patient developed blistering, ulcerations with infectious complications and pain and was severely disabled, consistent with grade 4 PPE. The lesions were located on both palms and soles (fig. 1) and required immediate hospitalization. The patient received treatment with oral pyridoxine, oral and topical steroids and pain killers, as well as locally applicated creams and emollients. After 1 week the ulcers were healing and the patient was discharged. Two weeks later, the skin lesions were completely healed while light erythema and tingling in the hands persisted. The chemotherapy treatment has since been reduced in dose, as recommended in table 1. 


\section{Literature Review}

Electronic searches were conducted using the Medline database for English-language records. The search terms used were 'palmar-plantar erythrodysesthesia', 'hand-foot syndrome', 'pegylated liposomal doxorubicin' and 'acral erythema'.

\section{Discussion}

A number of cytotoxic drugs have been reported to be linked to hand-foot syndrome, but it is most frequently associated with 5-fluorouracil, PLD, docetaxel, capecitabine, vinorelbine, gemcitabine and sorafenib [1]. PLD is a form of doxorubicin encapsulated within pegylated liposomes. This changes its biodistribution and prolongs drug half-life, which results in the decrease of toxic effects, especially cardiotoxicity [2]. PLD is approved for the treatment of patients with advanced ovarian cancer, metastatic breast cancer and soft tissue sarcomas.

The rate of hand-foot syndrome associated with PLD is increased compared to patients receiving conventional doxorubicin. The incidence of PLD-associated hand and foot syndrome reported by several authors is approximately $50 \%$ for patients with any grade of PPE, and approximately $20 \%$ for patients with grade 3 and 4 PPE [2,3], for a PLD dose of $50 \mathrm{mg} / \mathrm{m}^{2}$ every 4 weeks. The available evidence indicates, however, that a dose of 40 $\mathrm{mg} / \mathrm{m}^{2}$ every 4 weeks is at present considered equally effective and less toxic, and is therefore the preferred dosage [4].

PPE presents as a painful erythematous rash, often associated with edema, located on the palms, fingers and soles, occurring 2-12 days after administration of chemotherapy. It is preceded by dysesthesia. The rash may become bullous and ulcerative, associated with severe pain and interference with daily activities (table 1).

Histologic features of PPE are non-specific and based on a small number of patients. They include vacuolar degeneration of the basal cell layer, mild spongiosis, keratinocytes necrosis, papillary dermal edema, lymphohistiocytic infiltrates and partial separation of the epidermis from the dermis.

Perivascular infiltrates composed of lymphocytes and eosinophils are often seen in the dermis. There may also be evidence of eccrine squamous syringometaplasia or neutrophilic eccrine hidradenitis. Skin biopsies from 2 patients with PLD-associated PPE showed vacuolar degeneration of the basal layer of the epidermis, along with mild perivascular lymphocytic infiltration of the dermis, hyperkeratosis and apoptotic keratinocytes. Clinical, electrophysiologic and biopsy data suggest that small-fibre neuropathy may be the cause of pain and dysesthesia [5].

The pathophysiological mechanism of PPE is an area of active investigation. Factors involved could be rapid cell division in palms and soles, gravitational forces, vascular anatomy peculiar to these areas and temperature gradients in the distal extremities, as well as increased drug concentration in the eccrine glands of the palms and soles.

Research has uncovered the likely mechanism for PPE in patients treated with PLD. PLD is known to preferentially localize in both tumour and skin, with pre-clinical testing using murine models finding higher PLD levels in paws than in skin [6]. In another study, PLD fluorescence was quantitatively evaluated in humans using a dermatological laser 
scanning microscope. Three hours after PLD administration, fluorescence was observed in the uppermost part of the skin of the flexor forearm, palm, sole, axilla and forehead of a male patient [7]. A fluorescence signal was also detected, deep in the sweat glands and orifices of the palms, suggesting that the drug is transported by sweat to the skin's surface, perhaps facilitated by the hydrophilic coating of the liposome. Once on the surface of the skin, the drug was observed to be carried in sweat and to penetrate into the stratum corneum, which may serve as a reservoir, allowing penetration of the drug into the deeper layers of skin. Once penetration occurs, free radicals are formed and react with epidermal cells, leading to PPE. The palmar and plantar areas are characterized by high numbers of eccrine sweat glands that continuously secrete fluid and are thus most at risk for PPE.

Occurrence of PPE has been shown to be related to dose and prolonged drug exposure during continuous intravenous infusion, daily ingestion, as well as liposomal encapsulation of PLD which prolongs drug half-life. The use of cooling mechanisms, higher number of PLD cycles, and occurrence of mucositis, neutropenia, and peripheral neuropathy are possible predictors of PPE [8].

Even though severe grade 4 symptoms are not common and PPE has not been described to be a life-threatening condition, it can be disabling and impair the quality of life of the patient. Hackbarth et al. [9] analyzed the impact of dermatological toxicities on patients' quality of life. Their results showed that more than two thirds of patients developed a dermatological reaction (62.9\%) and felt significantly limited in pursuing their daily activities. PPE appeared to have a significant effect on overall health, as approximately $90 \%$ of patients with grade 3 PPE felt severely limited by this and approximately $70 \%$ even felt restricted in doing their work or other daily activities.

These data suggest that PPE as a side effect of chemotherapy constitutes an important factor limiting quality of life of patients, as is also shown in the present case.

The most effective management of PPE is treatment interruption, lengthening the interval between drug administrations or dose reduction of PLD. This normally leads to a rapid subsidence of symptoms, which usually resolve within 1-2 weeks.

The product information for PLD recommends dose modification in accordance with the clinical presentation and grade of PPE, which is shown in table 1.

Different measures have been suggested to prevent PPE symptoms, such as avoidance of friction, excessive pressure to the skin and extreme temperatures, and the application of creams $[1,4]$. A variety of creams and emollients have been shown not only to ease the symptoms of grade 1 PPE but even to prevent symptom development if used early enough. However, the efficacy of these measures has not been reported in controlled trials and emphasis is placed on the management of symptoms as they manifest and progress.

Agents like dimethylsulfoxide, oral and topical steroids seem to be effective for PPE symptoms of various grades, but none of them has been evaluated by randomized clinical trials $[1,3,4]$.

There are numerous case reports of the successful use of oral pyridoxine (vitamin $\mathrm{B}_{6}$ ) at doses up to $800 \mathrm{mg}$ daily for the management of PPE caused by a wide range of agents. In a case report, pyridoxine $100 \mathrm{mg}$ three times daily was used successfully to treat PLDassociated PPE [10]. In contrast to these case reports, a large prospective, randomized double-blind study evaluating the efficacy of pyridoxine in the prevention of 
capecitabine-associated PPE found no benefit [11]. Pyridoxine cream has been used alone or in combination with pyridoxine tablets for the management of PPE, but data are limited [1]. Pre-clinical data on animals support the efficacy of pyridoxine on PLDassociated PPE [12]. The use of pyridoxine for PLD-associated PPE is not well supported and it cannot be recommended outside the research setting.

Regional cooling via ice packs to the wrists and ankles during treatment with PLD has been suggested to be effective [13]. The theory behind this is that cooling results in vasoconstriction and therefore less drug circulation to the distal extremities, which may lead to less drug extravasation into the surrounding tissue, with reduced cutaneous toxicity as a result. The lower temperatures may also play a role in stabilizing the liposomal configuration of doxorubicin, leading to a reduced concentration of uncapsulated doxorubicin.

Mangili et al. [13] report the results of a prospective, observational and nonrandomized study of patients treated with PLD for gynecologic cancers. The patients received application of ice packs on the extremities and icicles during PLD infusion. They observed a statistically significant reduction in PPE incidence and severity. Their data suggest that a prolonged administration interval and the association with other agents do not reduce skin toxicity while patients receiving PLD at a lower dosage experienced handfoot syndrome less frequently. The use of regional cooling further reduces symptoms.

Although its efficacy needs to be proved prospectively in a controlled and randomized trial, the authors suggest that the introduction of the regional cooling strategy, together with correct instructions to patients regarding behavioral rules, could play a fundamental role in reducing the incidence of PPE.

While regional cooling appears promising for the prevention of PPE, data are not sufficient to support the routine use in clinical practice. According to the consensus-based recommendations of an international panel of experts, published in 2008, dose intensity modification is currently the most effective and best-documented approach to the prevention of hand-foot syndrome [14]. At a PLD dose intensity not exceeding 10 $\mathrm{mg} / \mathrm{m}^{2} /$ week (typically administered as $40 \mathrm{mg} / \mathrm{m}^{2}$ every 4 weeks), hand-foot syndrome is usually mild and easily managed and grade 4 PPE should not occur. While large, phase III randomized controlled clinical trials have not evaluated the effectiveness of dose intensity modification in the treatment of PPE, the available data and clinical experience suggest that this intervention most reproducibly impacts the natural history and severity of PLDinduced hand-foot syndrome. Therefore, patient education regarding the early signs and symptoms of PPE and the importance of prevention and early intervention using supportive care approaches are essential components in the prevention and management of PPE. Other strategies should be avoided outside the research setting, as their efficacy has not been demonstrated in phase III studies. Further research should be focused on conducting phase III research on PPE prevention and treatment. For example, pyridoxine, regional cooling and systemic corticosteroids have only limited data to support their use and cannot be recommended without the support of phase III data. 


\begin{tabular}{c|l|l|l}
$\begin{array}{c}\text { Case Reports in } \\
\text { Oncology }\end{array}$ & $\begin{array}{l}\text { Case Rep Oncol 2011;4:229-235 } \\
\text { DOl: 10.1159/000327767 }\end{array}$ & $\begin{array}{l}\text { Published online: } \\
\text { April 11, 2011 }\end{array}$ & $\begin{array}{l}\text { O 2011 S. Karger AG, Basel } \\
\text { ISSN 1662-6575 } \\
\text { www.karger.com/cro }\end{array}$ \\
\hline
\end{tabular}

\section{Conclusion}

Patients with recurrent ovarian cancer have a remote probability of cure, therefore palliation of symptoms, preservation of quality of life and prolongation of progressionfree survival are the primary treatment goals. An improved safety profile of PLD may result in an improved quality of life for patients with advanced ovarian cancer.

Hand and foot syndrome is a common skin toxicity in patients treated with PLD. Although the incidence of a severe grade of PPE is low, it can have a significant influence on a patient's quality of life and abilities. This needs to be taken into consideration when giving PLD treatment and modifying the dose. Preventive and treatment-accompanying measures may be advisable. The efficacy of these measures still needs to be assessed in controlled and randomized studies.

Table 1. Toxicity grades of PPE and dose modification guidelines for PLD

\begin{tabular}{lll}
\hline Grade & Clinical symptoms & Dose modification \\
\hline 1 & $\begin{array}{l}\text { Mild erythema, edema, or desquamation not } \\
\text { interfering with normal activities }\end{array}$ & $\begin{array}{l}\text { None, unless patient has experienced previous } \\
\text { grade 3-4 toxicity. If so, delay up to 2 weeks and } \\
\text { decrease dose by 25\%. Return to original dose } \\
\text { interval. }\end{array}$ \\
\hline 2 & $\begin{array}{l}\text { Erythema, edema, or desquamation } \\
\text { complicating, but not precluding normal } \\
\text { activities; blisters/ulcers <2 cm in diameter }\end{array}$ & $\begin{array}{l}\text { Delay up to 2 weeks or until resolved to grade 0- } \\
\text { 1. If there is no resolution after 2 weeks, PLD } \\
\text { should be discontinued. }\end{array}$ \\
\hline 3 & $\begin{array}{l}\text { Blistering/ulceration, or edema interfering with } \\
\text { normal activities; cannot wear regular clothing }\end{array}$ & $\begin{array}{l}\text { Delay up to 2 weeks or until resolved to grade 0- } \\
\text { 1. Decrease dose by 25\% and return to original } \\
\text { dose interval. If there is no resolution after 2 } \\
\text { weeks, PLD should be discontinued. }\end{array}$ \\
& $\begin{array}{l}\text { As for grade 3. } \\
\text { Infectious complications, bed } \\
\text { ridden/hospitalized }\end{array}$ & \\
\hline
\end{tabular}




\begin{tabular}{c|l|l|l}
$\begin{array}{c}\text { Case Reports in } \\
\text { Oncology }\end{array}$ & $\begin{array}{l}\text { Case Rep Oncol 2011;4:229-235 } \\
\text { DOl: 10.1159/000327767 }\end{array}$ & $\begin{array}{l}\text { Published online: } \\
\text { April 11, 2011 }\end{array}$ & $\begin{array}{l}\odot \text { 2011 S. Karger AG, Basel } \\
\text { ISSN 1662-6575 } \\
\text { www.karger.com/cro }\end{array}$ \\
\hline
\end{tabular}

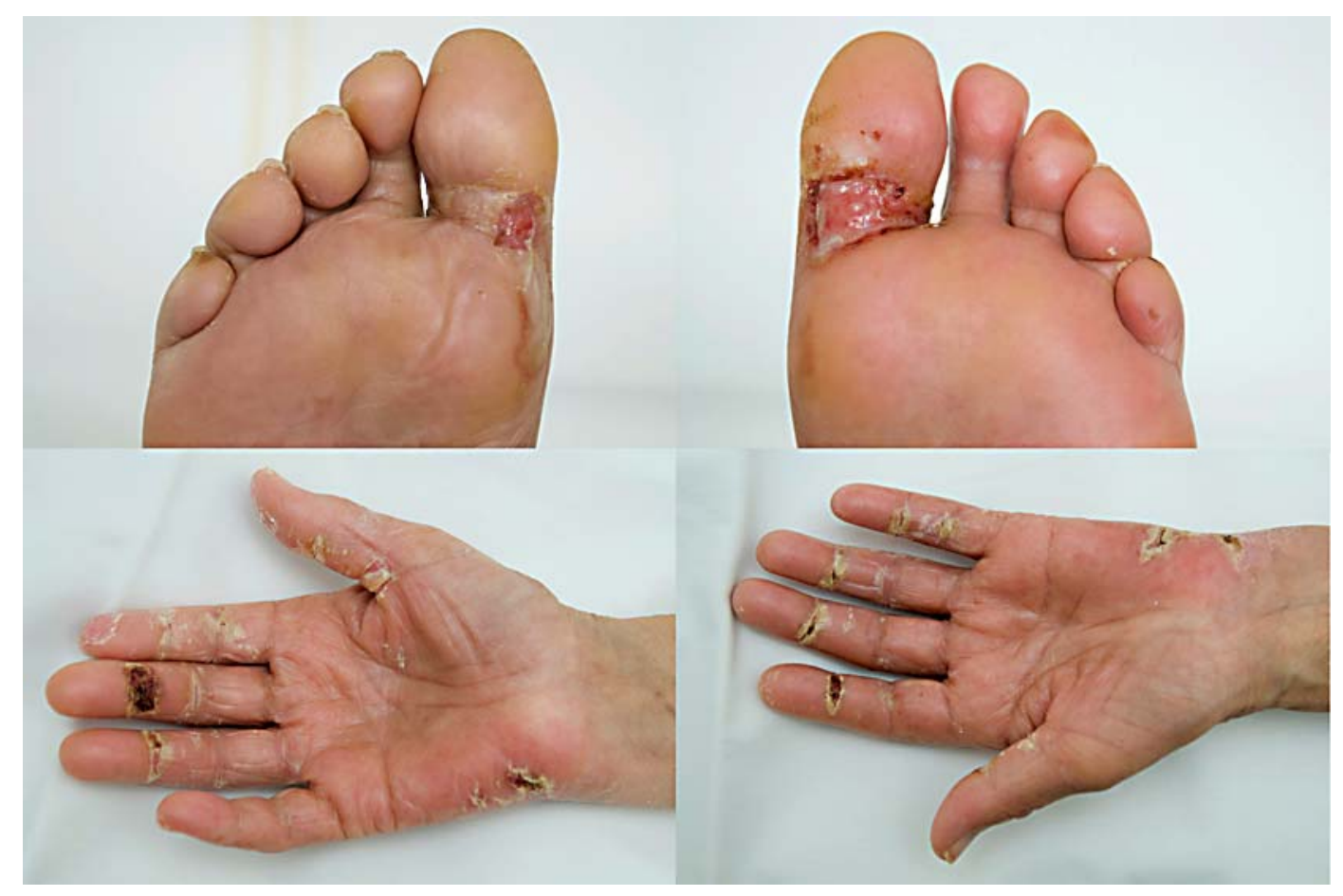

Fig. 1. Palmar-plantar erythrodysesthesia: blistering/ulceration of hands and feet interfering with normal activities after treatment with pegylated liposomal doxorubicin.

\section{References}

1 Webster-Gandy JD, How C, Harrold K: Palmar-plantar erythrodysesthesia (PPE): a literature review with commentary on experience in a cancer centre. Eur J Oncol Nurs 2007;11:238-246.

-2 O'Brien ME, Wigler N, Inbar M, Rosso R, Grischke E, Santoro A, et al: Reduced cardiotoxicity and comparable efficacy in a phase III trial of pegylated liposomal doxorubicin $\mathrm{HCl}$ (CAELYX/Doxil) versus conventional doxorubicin for first-line treatment of metastatic breast cancer. Ann Oncol 2004;15:440-449.

-3 Gordon AN, Fleagle JT, Guthrie D, Parkin DE, Gore ME, Lacave AJ: Recurrent epithelial ovarian carcinoma: a randomized phase III study of pegylated liposomal doxorubicin versus topotecan. J Clin Oncol 2001;19:33123322.

-4 Lorusso D, Di Stefano A, Carone V, Fagotti A, Pisconti S, Scambia G: Pegylated liposomal doxorubicin-related palmar-plantar erythrodysesthesia ('hand-foot' syndrome). Ann Oncol 2007;18:1159-1164.

-5 Gordon KB, Tajuddin A, Guitart J, Kuzel TM, Eramo LR, VonRoenn J: Hand-foot syndrome associated with liposome-encapsulated doxorubicin therapy. Cancer 1995;75:2169-2173.

6 Charrois GJ, Allen TM: Drug release rate influences the pharmacokinetics, biodistribution, therapeutic activity, and toxicity of pegylated liposomal doxorubicin formulations in murine breast cancer. Biochim Biophys Acta 2004;1663:167-177.

7 Jacobi U, Waibler E, Schulze P, Sehouli J, Oskay-Ozcelik G, Schmook T, et al: Release of doxorubicin in sweat: First step to induce the palmar-plantar erythrodysesthesia syndrome? Ann Oncol 2005;16:1210-1211.

-8 Tanyi JL, Smith JA, Ramos L, Parker CL, Munsell MF, Wolf JK: Predisposing risk factors for palmar-plantar erythrodysesthesia when using liposomal doxorubicin to treat recurrent ovarian cancer. Gynecol Oncol 2009;114:219-224.

\9 Hackbarth M, Haas N, Fotopoulou C, Lichtenegger W, Sehouli J: Chemotherapy-induced dermatological toxicity: frequencies and impact on quality of life in women's cancers. Results of a prospective study. Support Care Cancer 2008;16:267-273.

10 Hau P, Fabel K, Baumgart U, Rummele P, Grauer O, Bock A, et al: Pegylated liposomal doxorubicin-efficacy in patients with recurrent high-grade glioma. Cancer 2004;100:1199-1207. 
11 Lee S, Lee S, Chun Y, et al: Pyridoxine is not effective for the prevention of hand foot syndrome (HFS) associated with capecitabine therapy: Results of a randomized double-blind placebo-controlled study (abstract). Proc Am Soc Clin Oncol 2007;25:9007.

12 Vail DM, Chun R, Thamm DH, Garrett LD, Cooley AJ, Obradovich JE: Efficacy of pyridoxine to ameliorate the cutaneous toxicity associated with doxorubicin containing pegylated (stealth) liposomes: A randomized, double-blind clinical trial using a canine model. Clin Cancer Res 1998;4:1567-1571.

13 Mangili G, Petrone M, Gentile C, De Marzi P, Vigano R, Rabaiotti E: Prevention strategies in palmar-plantar erythrodysesthesia onset: the role of regional cooling. Gynecol Oncol 2008;108:332-335.

14 von Moos R, Thuerlimann BJ, Aapro M, Rayson D, Harrold K, Sehouli J, et al: Pegylated liposomal doxorubicin-associated hand-foot syndrome: Recommendations of an international panel of experts. Eur J Cancer 2008;44:781-790. 